\title{
Analysis on the Deep Influence of "Internet + Marketing" Platform on Fresh Agricultural Product Supply Chain
}

\author{
QiyanTian \\ Xi'anInternationalUniversity, Xi an,710077, China
}

\begin{abstract}
Along with the development of Internet technology, "Internet + marketing" platform emerges, and the supply chain of fresh agricultural products is developed and constructed under this platform. This marketing mode broadens the sales channels of fresh products, More convenient for people to buy fresh produce. This paper elaborates the composition of the supply chain of fresh agricultural products under the "Internet + marketing" platform and focuses on the deep impact of the "Internet + marketing" platform on fresh agricultural products supply chain.

Key words: "Internet + marketing" platform; fresh agricultural products; supply chain; deep impact

With the development of the times, the application of the Internet becomes more and more extensive. The network resources greatly enriched and facilitated the people's life. Especially in today, the Internet for our lives, study and work had a very important impact. China as a large agricultural country, the annual number of agricultural products produced is extremely impressive, especially meat, aquatic products and fruits and vegetables, such as the number of yearly output is increasing year by year trend. In this case, Premier Li stressed that in the "Internet + marketing" platform, to explore the sales channels of fresh agricultural products, in order to promote the development of the Internet economy, the Internet and fresh agricultural products closely together to promote its development.
\end{abstract}




\section{The agricultural product supply chain overview}

China's traditional supply chain system of fresh agricultural products is mainly composed of three parts, the first part is the production of agricultural products produced by farmers of the production system, the second part is the wholesale market, processing enterprises and distribution center consisting of transport, Processing and distribution system, the third part is by the large, medium and small supermarkets and retailers and various farmers market posed by the retail system. Fresh agricultural products must be through these three parts, consumers can access to innovative agricultural products, fresh produce to achieve your market circulation.

Today's society, the rapid development of Internet technology, followed by renewed supply of agricultural products supply chain system has also been affected, resulting in a huge change, fresh agricultural electronic marketing platform for homeopathy. This marketing tool is "Internet + Marketing" platform for the embodiment. In the "Internet + Marketing" platform, fresh agricultural products in the supply chain, the new changes are obvious. First of all, this part of the distribution of fresh agricultural products, fresh agricultural products because of the relatively short shelf life, people want to buy fresh fruits, vegetables and aquatic products, and they are also very easy to be corrosion, deterioration, its freshness Difficult to protect, so for its cold chain logistics distribution efficiency requirements are particularly high. However, if marketing through the "Internet + marketing" platform, you can market demand for fresh agricultural products to focus on information, and then through the "Internet + marketing" platform will be fresh in-kind agricultural products focused on the cold storage, The last in the cold chain logistics directly through the delivery, to reach the hands of consumers, greatly improving the distribution efficiency. Second, sales in this regard, "Internet + marketing" platform for the emergence of consumers, for its expansion of the purchase of fresh agricultural products channels, consumers can not go out at home to buy thousands of miles away fresh produce, Which allows consumers to enjoy a more favorable purchase experience. Finally, this paper focuses on the deep impact of the "Internet + Marketing" platform on fresh agricultural products supply chain.[1]

\section{The "Internet + marketing" platform for fresh agricultural products supply chain deep impact}

In the supply chain of fresh agricultural products in this part of its production system is critical, but also the circulation of fresh agricultural products based on the conditions, only agricultural producers to produce agricultural products can be lively agricultural products sales. At present, China's agriculture is a small-scale agricultural production, which will appear a lot of fresh produce cannot find its specific production and farmers sales channels difficult, poor sales of fresh agricultural products and other issues. The "Internet + marketing" 
platform for the emergence of China's agricultural development is no doubt a new way of development, through the "Internet + marketing" platform, you can talk about fresh agricultural products to the platform for fresh produce after the output Broadened its sales channels, farmers are no longer for the poor sales of fresh agricultural products feel anxious, thus increasing the enthusiasm of the farmers, not the farmers to increase their income. At the same time, the majority of farmers can also "Internet + Marketing" platform for feedback from the market demand for information back to adjust the plan for fresh agricultural products, to avoid the market supply of excess, cannot load the situation. For example, in 2016, the market demand for garlic is very large, the market price has reached more than 8 a pound, through the "Internet + marketing" platform feedback from the information, farmers in the comprehensive consideration, will be 2017 Appropriate increase in the number of garlic cultivation. In recent years, with the development of science and technology, China has more and more emphasis on agricultural modernization, and the emergence of "Internet + Marketing" platform will inevitably lead to agricultural reform and accelerate the modernization of agriculture in China.[2]

Today, we can say that "Internet + Marketing" platform for fresh agricultural products industry has added new vitality. "Internet + Marketing" platform marketing of fresh agricultural products to become a new business marketing. "Internet + Marketing" platform as a communication and exchange of the bridge, the producers and consumers closely linked. Through the $\mathrm{O} 2 \mathrm{O}$ model, fresh agricultural products supply chain will be products, capital, business information and other operations, mainly for the online agricultural production as a prerequisite, on this basis, the various fresh produce together, the type is complete, While the quality can be protected, the price is still relatively low. Online, through the operation and operation of the Internet, so that more and more consumers to choose and buy, in understanding "Internet + Marketing" platform provides quality services, consumers can purchase fresh products. All the large, medium and small supermarkets and retailers who can rely on the Internet, independent development of their own business conditions for the "Internet + marketing" platform and Internet marketing Web site, and their own characteristics expressed through the Internet, for their own fixed Customer groups.

\section{The "Internet + marketing" platform for fresh agricultural products}

In 2015, China's State Council issued "on the development of e-commerce to speed up the development of new economic impetus to the views of", after the release of this opinion, the Chinese government began to support rural e-commerce work, to provide substantial financial support to ensure its Operational development. At the same time in order to "Internet + Marketing" platform to develop better and better, the state also let some technical personnel 
for the "Internet + Marketing" platform construction work to help and guide, is to promote rural e-commerce development. In addition, the "Internet + marketing" platform for farmers to produce agricultural products produced by the broadening of the sales channels, farmers in the production of products, through the "Internet + marketing" platform for sales, not simply rely on the traditional Sales channels, to solve the farmers produce fresh agricultural products, the sale of the problem.[3]

"Internet + Marketing" platform, people can be online through the fresh agricultural products related to the site or platform to buy their own needs a variety of fresh agricultural products, saving people to the supermarket to buy products, time and effort. Today's society is a fast-paced society, people's survival pressure, busy, less time, after get off work, people are usually reluctant to go to the supermarket for fresh produce to buy, and get off work time is the supermarket traffic is relatively large time, Usually at this point in time to go to the supermarket to buy fresh produce takes a long line, but through the "Internet + marketing" platform, businesses can purchase fresh produce consumers packaged, and then provide door-to-door service, which No thought to save people's time, save time and effort to meet the people's production needs.

Focus on the "Internet + marketing" platform for sales of fresh agricultural products must go through layers of quality inspection, only in line with product sales requirements, will allow the "Internet + marketing" platform for sales, therefore, which in the To a certain extent, protect the quality of fresh agricultural products, but also to meet people for pure natural green products. At the same time, through the "Internet + marketing" platform to ensure that fresh agricultural products in the supply of fruits and vegetables more adequate, such products in fresh produce already occupies a major position, but also has a strong seasonal, the proposed "Internet + Marketing "platform allows people to buy seasonal fruits and vegetables, more welcomed by the people.

At present, through the "Internet + marketing" platform, marketing fresh agricultural products, although more time-saving, but through this virtual platform, consumers can not effectively see the fresh agricultural products, only by the seller of video, Evaluation as the basis for judging the quality of fresh agricultural products. And "Internet + marketing" can not be achieved when consumers immediately after the purchase of products can access the advantages of fresh agricultural products must go through the logistics and distribution to reach the hands of consumers, and in the distribution process, fresh agricultural products Quality can not be effectively protected, there will often be clearly sellers selling fresh agricultural products of good quality, flawless, but consumers receive the goods found after their products completely substandard, or even damaged, leading to buyers and sellers Between the emergence of a large number of "war of words" to solve them is very difficult, which are basically due to the distribution process of the problems caused by.

At present, China's "Internet + Marketing" platform online or offline need a lot of financial support, but after the profits, the specific dividend model is not reflected. At the same time through the "Internet + marketing" platform, you need to focus on fresh produce, put it in the cold chain of cold storage, but the specific 
construction of the corresponding imperfections, and high transport costs, must have a lot of money Construction and improvement. In recent years, due to funding strand breaks leading to "Internet + Marketing" platform is difficult to carry out a lot of examples. At the same time there are still some "Internet + marketing" platform for false propaganda, exaggerated the phenomenon of publicity, leading to many consumers "Internet + marketing" platform lose confidence, no longer willing to "Internet + marketing" platform to buy fresh agricultural products.

\section{Fresh agricultural products, "Internet + marketing" platform for urgent needs}

With the emergence of China's "Internet + Marketing" platform, it changed the situation of the original fresh agricultural products affected by the production areas and seasons, and changed the trading space to increase the circulation efficiency of fresh agricultural products. Therefore, in order to ensure the quality of fresh agricultural products and circulation efficiency, to ensure that agricultural producers, retailers and consumers of the three economic interests of China's fresh agricultural products enterprises must strengthen the cold chain distribution, at present, China's cold chain Construction, compared with foreign countries, but also far below the standard, can not be truly full name of cold chain distribution, which is particularly vulnerable to the quality of raw material consumption is particularly high, consumers buy fresh produce, Of the purchase experience is very poor. Although China's cold storage capacity has reached more than 80 million flat, but because of China's population is relatively high, the per capita relative level is bound to be relatively low, so China's cold storage construction there is a relatively large room for growth.

At present, China's large-scale fresh agricultural e-commerce enterprises compared to small fresh agricultural products e-commerce enterprises, has not yet formed a unified production scale, its operating costs are relatively high, investment is still relatively large, specifically in cold storage construction is not in place, Its sales results are not obvious. The small and medium-sized fresh products e-commerce companies rely on the "Internet + Marketing" platform to do a variety of agricultural products to include them, and inexpensive than fresh large-scale e-commerce companies more popular with consumers. They are located in the vicinity of residential areas, and the development of the corresponding social software for marketing, although relatively small, but flexible capital operation, services in place, the progress is very smooth.

\section{Acknowledgements}

The research work was supported byShaanxi Provincial Department of Education special research project, project number 16JK2170,Topic: Internet + Shaanxi F2F model of fresh agricultural products and implementation of the program 


\section{References}

[1] Wang Xuhui, Zhang Qilin. Intrinsic Mechanism of Cracking Down on Circulation Dilemma of Fresh Agricultural Products by E-commerce - A Comparative Study of Two Cases Based on the Livestock of Tiancao and Tuotuo Workers' Association [J]. China Soft Science, 2016,02: 39- 55.

[2] DAN Bin, ZHENG Kai-wei, LIU Mo-lin, SHAO Bing-jia.Study on C2B Business Model of "Internet + " Fresh Agricultural Supply Chain Based on Community Economy $[\mathrm{J}]$. Business Economics and Management, 2016, 08: 16-23.

[3] Zhou Yu. "Internet + marketing" platform for the deep impact of fresh agricultural products supply chain [J] modern food, 2016,13: 19-22. 